\title{
CARTA ABIERTA
}

\section{Sr. Doctor Eduardo García Máynez, Director de Diánoia}

Estimado colega y amigo:

Primero con sorpresa, con indignación después, por último con la indefinible y casi fisiológica lástima que estos revueltos tiempos me producen, he visto en Diánoia de 1962 - el excelente Anuario de Filosofía bajo su digna dirección- una extensa crítica sobre mi libro Ortega y su filosofía. Coleccioné en él ensayos ya publicados, del más variado origen, enfoque y nivel. Uno hay que fue escrito en lucha contra el reloj, mientras esperaba la linotipia caraqueña y en Madrid velaban un cadáver. Entre otras páginas de más serena meditación, tampoco falta al. guna de vena periodística: Ortegá, en una anécdota, por ejemplo. No pretendía además - y así lo dije en el prólogo - presentar al lector una exposición en forma sobre la filosofia de Ortega. Entre otras razones al caso, cuando el original salió para la imprenta faltaban aún muchos inéditos del filósofo. La intención del libro, por tanto, es mucho menos que eso, aunque también mucho más. No es difícil exponer, con ayuda de papeletas y desde fuera, esta $\mathbf{u}$ otra filosofía. Ya hay bastantes libros sobre el filósofo de la razón vital con tal receta metódica y punto de vista tan aséptico. El mío - y esto también se advierte en el prólogo — sólo se titula "Ortega" y "su filosofía", precisamente por las dos tendencias máximas de sus páginas: una búsqueda del perfil espiritual del filósofo - - dando al paso algún material vivo a modo de documento-, y un interpretar el núcleo esencial de su metafísica. Son dos tareas de empeño, que no todo el mundo se permite, sobre todo porque casi por fuerza están ambas condenadas al fracaso. Pero este peligro, lejos de arredrar, ¿no incita de veras al esfuerzo? Ya ve usted que no sólo me decidí a publicar el libro, sino que hoy lo defiendo en público. ¿Necesito añadir, por tanto, que aún sigo concediéndole cierto mérito? No vea usted, sin embargo, vanidad alguna en mis palabras. Yo siempre la he despreciado profundamente. Piense, además, que el vanidoso nunca da la cara por lo suyo: mendigà ajenas alabanzas. Considérelo orgullo, si quiere. Aunque mi orgullo me dice, que si algo queda en su día de mi labor, en modo alguno debo esperarlo de este libro de circunstancias. Con él me he limitado a cumplir un noble deber de discipulo -y esto sí me enorgullece, y esto sí es necesario proclamarlo bien alto y a los cuatro vientos en esta época nuestra de conciencias empecinadas-. Le cuento todo esto para justificarle mi sorpresa. Plenamente consciente de lo que pueda haber de valioso en mi libro, también lo soy de sus límites. Y es por esto que no esperaba merecer el honor de'un análisis en revista tan especializada y exclusiva como Diánoia. En modo alguno cảrecía de fundamento mi sentir. Lo prueba la compañía misma que la ocasión me depara: Hartmann, Collingwood, Peter Geach, e incluso la de una exigente antología con páginas de Einstein, Whitehead, Reichenbach y otros hombres semejantes. Lo que no me acompaña 'es ningún apellido castellano. ¿Tan pobre anda nuestra bibliografía filosófica? No lo creo yo así. Y en la mente de todos está que había libros más enjundiosos y eruditos que el mío para tan alta distinción. E incluso sobre el mismo tema.

La sorpresa, en realidad, ha sido doble. $\mathrm{Y}$ es en su segundo aspecto cuando se tiñe de indignación. Sería obvio recordar -si hoy no se ocultaran como aver. 
gonzadas de sí mismas- ciertas normas elementales de trato y convivencia en la vida intelectual. Como la búsqueda común se orienta esencialmente bajo el imperativo de la verdad, siempre se han sacrificado a ésta las ideologías y resentimientos. La verdad no empece, desde luego, los más arriscados modos de censura. Nunca ha faltado, incluso, algún desaforado adalid de una buena causa. Confesemos, no obstante, que en número mucho menor al de los incontables energúmenos de la consigna. Y lo cierto es que hoy priva ésta - la consigna, y no la verdad- en las llamadas revistas de combate y en los periodicuchos mercenarios. Tras esas barricadas se rien de las viejas normas, viven de falsedades y se drogan con la injuria. A veces el odio a la verdad es tan fuerte, que les incita al satánico placer de la calumnia. No sólo en Dinamarca; también hay algo que apesta en todo este mundo nuestro. Como dice ingeniosamente el proverbio francés, c'est par la tête que le poisson pourrit. Añadamos nosotros que no hay peor podredumbre que la del espíritu. Y el caso es, que por un elemental resto de com-patía -me niego en este momento a escribir la palabra usual, digna de más noble empleo-, esa peste adivina en el espíritu sano su peor enemigo. Por eso se ha vuelto tan áspera la vida intelectual. Hoy más que en sus felices años tiene razón Rubén Darío: "El oficio de pensar es de los más graves y peligrosos sobre la faz de la tierra." Y otro poeta - también con bronca sonoridad castellana- supo dar cabal explicación de ese peligro: "Las batallas se ganan entre ceja y ceja." $\mathrm{Y}$ bien sabía el poeta de ambas cosas, pues se trata de José Martí. De ahí el odio actual a la inteligencia. Nada de esto - es evidente de suyo - se insinúa siquiera recordando a Diánoia. Es un Anuario digno y serio que merece todo mi respeto. Es más: creo está cumpliendo, con otras cuantas revistas de las universidades hispanoamericanas, una labor callada, aún no reconocida en todo su valer, que muy pronto tendrá importante cuenta en nuestra historia. Pero de ahí vino justamente mi sorpresa segunda. Debo apresurarme a manifestarle, amigo García Máynez, mi pleno convencimiento de que el más sorprendido y enojado ha sido usted. Quien sabe cumplir una tenaz labor durante años, jamás se decide a arrojarla por la borda en el arrebato del instante. $Y$, sin embargo, la causa de esa sorpresa, el hecho mismo que la motiva, está por sus páginas en tinta y sangre. Por esto, que la sorpresa se ha contagiado de indignación.

Por muy agresiva que fuere la censura a cualquier libro, cuando es-justa y fundada sólo cabe el silencio. Éste es el mejor cómplice. También es aconsejable ante el desafuero. Se ha hecho tan usual en nuestros medios la nocturna prosa de comando - desde luego, en papeles ni siquiera buenos para envolver-, que la simple respuesta ya involucra un ingenuo hacer el juego. Pero, ¡en las pulcras páginas de Diánoia! i $Y$ de modo tal, camuflado bajo el manto de la serenidad y el rigor científico! Porque ése ha sido, amigo García Máynez, el recatado estilo de la crítica que comento. Más que vocear sus palabras, las envenena. Por mi parte, ya pueden gritar los críticos cuanto gusten $-\mathrm{y}$ sus gargantas lo permitansobre las tesis de mis libros; se entiende, claro está, en los límites de las tesis mismas y sin faltar a la verdad y al respeto. Sé muy bien que no todos pensamos lo mismo. Y también sé que sólo intenta vencer quien no convence. No soy de los que piensan - pues ello iría precisamente contra lo más hondo de mi sentir- que pueda posarse la verdad en mi mano ni en la de nadie. ¿Necesito recordarle al caso mi Comunicación al Congreso de Filosofía en Santiago de Chile, titulada Ser, Verdad y Progreso? En mi entender, vamos haciendo precarias verdades día a día y, éstas son nuestro pan cotidiano. La Verdad misma, ésa que siempre se escribe con mayúscula, se esconde más allá de nuestro esfuerzo, sorda e inalcanzable. No 
hay escepticismo en ello, sino un simple reconocer, con la humana grandeza, su finitud y límites. La Verdad no es de nadie. No obstante, también sé muy bien que están ahí, afortunadamente, esas otras verdades segundas, de carácter casi instrumental, tan útiles y serviciales a nuestra vida en todos sus niveles. La mayor estupidez del hombre consiste en no saber respetarlas. Quien así procede ni a sí mismo se respeta, pues se rebaja en su propia dignidad humana. Nuestro maravilloso siglo, el siglo de la técnica, lleva muy en la sangre, sin embargo, este ultrajar verdades, este negarlas por capricho, y para nadie es un secreto que dicho odio a la razón constituye la peor lacra de nuestro tiempo. Es en cierto modo un caldo de cultivo, acaso ocurrencia del mismo diablo. Desde ese caldo se produce la nueva invasión vertical, la del bárbaro que Ortega ha bautizado como hombre-masa. Éste es un puro nisus voluntatis. Como carece de razón, ya no es un nisus rationis, la odia profundamente y pone en su sede la consigna. Por eso se agrupan las gentes de hoy bajo una enseña partidista. Por eso proceden violentamente en todo. Les exaspera escuchar razones y verdades que no comprenden. $\mathrm{Y}$ más que nada, el escuchar las razones verdaderas de su propia incomprensión. En el fondo, el máximo resentimiento contra Ortega procede precisamente del gesto audaz que tuvo, por haberse permitido poner un espejo ante los ojos del hombre-masa. Hasta la séptima generación lo han maldecido, a juzgar por las muestras, pues la supurante inquina de tal horror aún se babea sobre los discípulos. $\mathrm{Y}$ de ahí que coincidan hoy dos jaurías muy opuestas en perseguirles. Dicho sea con todo respeto, también hay en el otro polo una hipertrofia de conciencia partidista. Unos y otros, cuando en vano asoman los colmillos, recurren a la falsificación. No hay escrúpulos cuando todo se justifica. $Y$ algo muy íntimo, demasiado íntimo acaso, les compulsa, pues sin duda se complacen en manchar como mecanismo de defensa.

Pero demos de lado estas consideraciones generales. Ahora sólo se trata de esa crítica a mi libro en las pulcràs páginas de Diánoia. Y le decía a usted que el estilo moral que ella rezuma descargaba mi indignación. Y créame que no sólo por simples razones personales, sino por más altos intereses. Ahora comprenderá usted que todo ese largo inciso anterior, inoportuno a primera vista, era en rigor inevitable y debía anteponerse. Pues el motor de mi denuncia se cimenta sobre dicha situación. Lo qué acerca de esa crítica debo decir en conciencia -y esto de la manera más tajante, con la más bronca voz-, es que odia la verdad hasta el tuétano, pese a sus aires axiológicos y científicos. Y se evidencia este odiar porque falta a la verdad constantemente, porque la desprecia en su forma misma, en cuan. to ni siquiera se preocupa de encubrir la contradicción entre el sugerir y lo que cita. $\mathrm{Y}$ aunque critica un libro, y con éste a su autor, nada menos que desde tan alta tribuna, la consigna o el resentimiento le justifica en su conciencia el no leerle, el consultarle sólo a salto de mata, y ello como inspiración y droga a la inferencia humoral. Es evidente que todos los juicios se disparan desde una inquina de no sé qué origen contra Ortega - aunque me lo imagino-, y así se goza en satisfacerla. Ortega - según se comprueba a cada paso- es una de sus bestias negras. Una y otra vez lo. demuestra, de manera explosiva y hasta la saciedad. Por eso, quien esté cerca corre serio peligro.

Me interpretaría usted mal si creyera que mi dolorido sentir, que mi reacción última, provienen únicamente de este ataque o de la injusta presentación del libro y la implicada censura al autor. Es más: ni siquiera proceden de ese estilo crítico en si mismo - pues ya no es novedad - por el cual la violencia retuerce el cuello a filosofemas y árgumentos. Lo más grave a mi modo de ver, lo que desata mi repulsa mayor, sin duda tiene mucho en común con la indignación que usted mismo 
habrá sentido. ¿Cómo es posible que pueda aparecer en las páginas de Düanoia - vocacionalmente iluminada por la serena mirada de Minerva - tal desenfreno de la razón y la verdad? Ya le decía que nuestra época apesta. Todos lo sabemos demasiado bien, pues ese olor penetrante nos asfixia. Pero algunos contábamos' $-y$ aún seguimos contando, pese a todo- con la serenidad de ciertos rincones donde se guarece el espíritu y halla defensa la razón. Ésta es nuestra esperanza. Al menos, creo, quiero creer, que un día cercano remitirá esta alta fiebre de violencia que padecemos. No por sí sola, claro está; no espontáneamente. Toda enfermedad debe ser diagnosticada para la terapéutica idónea. Y de médico del espíritu sólo sirve el intelectual de casta, el auténtico. Sólo quienes de veras sientan la dignidad humana y oigan resonar en lo íntimo la responsabilidad del quehacer, sólo ésos serán posibles salvadores del hombre actual, sólo éesos le curarán su enfermedad ontólógica. Para que el milagro se logre, no podemos dejarles solos. Esas mentes agudas y perspicaces necesitarán la colaboración de otros hombres que les comprendan, que sientan dentro de sí la llamada de una nueva vocación - sólo laica en su tema- que les lleve a misiones para curar espíritus. Porque la enfermedad ontológica del hombre - reducido a nisus voluntatis - nos obliga a una plural y repetida logoterapia colectiva. Ya es urgente el remedio. Nuestro mayor peligro es más solapado que el de la bomba atómica. La radiación ya está en las almas. Para apreciarla no hacen falta contadores Geiger. Por eso es que hoy la esperanza se cifra más que nunca en esos rincones de serenidad donde el intelectual responsable - poeta, artista, científico o filósofo- se pone en forma para su misión, enciende en su mente la nueva luz del mañana, comienza a llamar al futuro por su nombre. Así lo siento, al menos. Como Martí, también creo que las batallas se ganan entre ceja y ceja. Pero no desde una sola frente. - También en el espíritu cuenta el número. E importa mucho que crezca, pues se prepara otra gigantesca agonía cosmogónica muy semejante a la cantada en el Enuma elís. Sólo que hoy las huestes subterráneas han asimilado la experiencia. Sin confesarlo, saben muy bien que la infraestructura radical es de la misma estofa que nuestros sueños. Ahora son campo de batalla las conciencias. Por eso tratan de introducirse en tal campo enemigo; naturalmente, con sus propias armas: las sinrazones y consignas.

¿Y la crítica misma que da pie a estas reflexiones? Ya comprenderá usted que desde esta hora de vísperas ni merece la pena. Ya la he desmontado, por lo demás, casi punto por punto, en las acogedoras páginas de La palabra y el Hombre; otra revista de honroso título. En su número 23 (julio-septiembre, 1962) verá mi Réplica al crítico Bueno. Ahora de buena gana pondría el punto final. Ya dije que el libro no importa; y que todo libro se las entiende solo a la larga, pues no hay elogio que aumente su valer ni poder censurante que le arranque lo propio. Sin embargo, una circunstancia me obliga. Como he calificado dicha crítica de mendaz, debo justificar la apelación. Desde luego, es tan servil la palabra y tan déspota de ella el hombre, que innúmeros matices del más torpe decir se escapan por la más fina malla detectora. Dejémoslos, pues, fugarse. Pongamos sólo una malla de ocho hilos al presunto "rehilar" ideas de esa crítica.

Primero. Presenta el libro dos series de ensayos: literarios y filósóficos. Convendría usar dos criterios. Secretamente se emplean, sólo que al revés. Dice de los primeros: "Notas obituarias, elegías o necrologías, en las que se toma alguna motivación de su doctrina sin que llegue a ser esencial, ni mucho menos desen. vuelta con el orden que requeriría una exposición de mayor profundidad." Y de los últimos: "Se refieren ocasionalmente a las ideas de Ortẹga; podríamos decir 
que son una especie de ensayo sobre el ensayo, perspectiva en torno a la perspectiva, circunstancialidad referida a una filosofía circunstancial." Huelga todo comentario. Por sí mismo lo hará el lector, preguntándose: ¿Por qué, entonces, se nos somete a audiencia en tan selecta revista?

Segundo. Promete el crítico "rehilar" ideas y presentar "contenidos". Y justaménte ante cada ensayo, nota o artículo. Dado el aparato externo a tal tarea, bien parece cumplir. Pero más de una vez falsea, falsifica esos "contenidos", e incluso la significación misma de algunos títulos. Así procede, por ejemplo, con La ense. ñanza de Ortega y sobre todo con Ortega o la muerte incompleta.

Tercero. Otras veces no falsea precisamente los "contenidos"; se limita a enturbiarlos de tal modo en la confusión de sus frases, que en lugar.de espejo funciona como cobija. Y en la mente del desprevenido lector se sugiere así un verdadero caos del material criticado. ' $O$ es que no han prejużgado de caóticos, quienes no conozcan el libro mismo, estos ensayos: La vigilia de Ortega, La Escuela de Madrid, Teoría de la predicción histórica, Ortega y el trasfondo filosófico de la microfísica?

Cuarto. He aquí, una vez más, el burdo truco de moda. Escribe el crítico: "Expone el propio Granell." Y a continuación me hace decir, entrecomilladamente y en efecto con mis propiàs palabras, un supuesto subrayar la "indocumentación" de Ortega en materia estética. Pero se guarda mucho de mencionar las líneas precedentes de la misma oración. Y éstas rezan: "Y en las mentes de dichos contertulios, cuando aducen tales ejemplos de yerros orteguianos, hay estos dos pensamientos contradictorios:" Ya ve el lector que estas líneas citadas terminan en dos puntos. ¿Puede, pues, permitirse nadie, sin menoscabo de la ética profesional, calificar como de mi propio pensamiento las palabras - sin duda escritas por míque sigan a esos dos puntos? (Cf. la página 63 del libro.)

Quinto. Estamos en el mismo trabajo anterior: Ortega y su circunstancia. Fue un artículo de encargo para revista no especializada cuando murió el filósofo. $Y$ así se advierte en nota preliminar. Su`tema, al parecer, se añeja cómo el buen vino: la incomprensión que halló entre los intelectuales de habla castellana. Al final y al paso digo que su máxima aportación fue "una metafísica nueva". El crítico se sonríe: "No dice por el momento en qué consiste tal metafísica." Y sin duda no miente, pues se guarece tras este burladero: "por el momento". Sólo que lo transforma en una eternidad, ya que no vuelve a hablar de ello. Con sólo volver la página y leer el ensayo siguiente - La Escuela de Madrid - hubiera hallado respuesta. E incluso, en la apretada forma de unas conclusiones, pues originariamente había sido escrito para un Congreso de Filosofía que no llegó a realizarse.

Sexto. No cabe duda. El crítico sólo ha leído a salto de mata. Y es así - como diría Quevedo- que su crítica resulta asalto a matar. ¿O no hay intento de asesinato moral cuando se insinúa vesania en los escritos de un profesional de la filosofía? Pues tal es justamente lo" ahora insinuado: "Se trata, como puede suponerse, de convertir el inmortal pintor español en una especie de precursor orteguiano, por más exaltada que parezca esta perspectiva de Granell." ¿Le ha llevado a tal conclusión el título de este ensayo: Velázquez o la realidad como perspectiva? Nada de eso. El crítico es muy serio y se atiene a los textos: "¿No se comprende ya -y en su más profunda razón- que el fílósofo del perspectivismo ve en el autor de ese agudo tratado de Metafísica, que es el lienzo Las Hilanderas, un espíritu afín y casi precursor al suyo?" Tal es el texto mío - desgarrado de su contexto--. Y aun así, desgarrado y solo, contradice al crítico, pues en todo caso 
tampoco sería yo, sino "el filósofo", quien tal pensase. Y renuncio a todo aclarar y referir a la totalidad del ensayo. Cualquier lector sin malevolencia y de mentalidad media puede hacer el análisis por sí mismo y sin contexto.

Séptimo. Ortega y el trasfondo filosófico de la microfisica. Son casi cincuenta páginas -entre las doscientas del libro- dedicadas a exponer, como hipótesis de trabajo, la posible relación indicada en el título. Ni una sola palabra de crítico tan entusiasta por la ciencia hace eco a esa hipótesis. Se limita a embestir a Ortega, a citar ampliamente palabras marginales - que no ha comprendido, como demuestran las fáciles chispas de su ingenio - y termina regalándome, caritativa y generosamente, "una exposición de filosofía de la historia". Rectifico: no era tan generoso su regalo, pues se cobra por adelantado: "Aunque tiene muy poco que ver con la microfísica." Ya comprenderá el lector que no hay nada cierto en tal historia.

Octavo. Seré más extenso en este último punto -último de los aquí subrayados-, pues acaso merezca algún interés del lector, al menos en cuanto problema muy debatido. Resume así el ensayo titulado El sistema de Ortega: "Defiende la existencia de un sistema en Ortega, cosa que se ha dudado intensamente en los círculos que defienden la posición científica de la filosofía." Y añade: "Este artículo es decepcionante, ya que, contrariamente a lo prometido, no se demuestra el presunto sistema orteguiano." Aunque la crítica aparece en una revista especializada, en ningún momento se toma el trabajo de perfilar exactamente la idea de sistema que el ensayo adelanta, de modo que la condena sin análisis. Pero hay más. Voy a recoger, aquí las dos observaciones que le hice en la revista de la Universidad Veracruzana, La Palabra y el Hombre: "Primera: Yo no he dicho en ninguna parte que la aportación de Ortega 'es' un sistema, ni que su pensar esté expreso en forma sistemática. El lector puede comprobar, al comienzo de mi larguísima nota 3, estas palabras: 'Ya comencé por admitir el carácter asistemático en el ropaje de sus escritos.' $\mathrm{Y}$ se dice en el texto mismo: 'Hay un sistema en Ortega. A hora veremos los matices de ese haber' (pág. 132). Para quien no recaiga en concentrada impropiedad, del ser al haber hay un buen trecho. Mi tesis consiste en esto: Hay en la obra orteguiana un núcleo generador de sistema: su idea de la realidad radical, que llama vida. Desde luego, la idea de la vida parece rebelde a una estructurada racionalización. De ahí que se haya considerado su pensamiento como forzosamente asistemático; impresión que se fortifica ante el estilo de su pensar. No obstante, Ortega insistía en su voluntad de sistema. ¿Quién tiene razón? Yo he observado que al interpretar la vida como mutua inmanencia - según expresión tomada de Whitehead-, los diferentes análisis que Ortega iba haciendo desde abajo inciden siempre sobre el mismo núcleo. Este núcleo parece ser, por tanto, un generador de coherencia sistemática. Hay, pues, un íntimo sistemá en Ortega, hay en su pensar unidad orgánica, aunque no se explicitara en forma. Yo esperaba - cuando en 1955 expuse esta tesis- que apareciera entre sus papeles alguna anotación al respecto, aunque sólo fuere un esbozo de indole personal. Si se ha hallado o no tal nota, en nada puede empañar la verdad de lo dicho. Segunda observación: Es falso que yo hayā prometido demostrarlo. Tal promesa equivaldría a la construcción misma del sistema. ¿Cómo puede pensar un investigador de la filosofía que sea fácil hacerlo en menos de doce páginas y superando con ello al propio Leibniz en concisión y profundidad? No existe tal promesa. Pero, hay más: ni siquiera se intenta una demostración de la tesis misma. Mis exactas palabras fueron éstas: 'Me limitaré... a la mostración ejemplar de su fundamento.' Y conste que el texto lleva estas mismas cursivas (pág. 135). 
Para esa mostración ejemplar puse dos ejemplos: la doctrina de Ideas y Creencias y la teoría de la historia. Si mi tesis es cierta o no, si he logrado mostrarla o fracasé en el intento, eso ya es otro cantar. Sobre ello podrá el crítico opinar libremente cuanto quisiere. Pero, no me haga decir. . lo que no he dicho."

Bien puede creerme, estimado amigo: es muy desagradable este salir a la palestra en propia defensa. Si el crítico no hubiera llegado a ciertos límites intolerables, que condenan las más elementales normas de convivencia, ni siquiera hubiera respondido. Ya le he dicho que los libros se defienden solos. Mas, puesto a salir, salgo de cuerpo entero, dando todo el peso de responsabilidad a mis palabras y elevando de paso a denuncia la defensa. Algo apesta en nuestro mundo, decía. No dejemos que esa putrefacción del espíritu enfermo se adueñe de los rincones donde el espíritu sano sueña sanamente el mañana.

Le ruego, doctor García Máynez, que recoja en las páginas de Diánoia esta carta abierta. Le anticipa las gracias y le saluda cordialmente,

Caracas, 28 de agosto de 1962.

Manuel Granell 